\section{NOVAS TECNOLOGIAS, A BUSCA E O USO DE INFORMAÇÃO NO ENSINO MÉDIO}

\author{
Anderson Messias Roriso do Nascimento* \\ Kelley Cristine Gonçalves Dias Gasque
}

RESUMO

\begin{abstract}
O artigo resulta de pesquisa de doutorado sobre como os jovens do ensino médio buscam e usam a informação por meio das novas tecnologias para a formação escolar. A pesquisa é de natureza qualitativa, com a realização de grupos de discussões em três escolas privadas do ensino médio, sendo uma de formação profissional e tecnológica do Distrito Federal. O método documentário fundamentou a análise dos grupos de discussão. Os resultados mostram que os estudantes percebem o ensino médio como "treinamento" para o vestibular. As escolas não desenvolvem estratégias para o ensino da busca e do uso da informação. Os estudantes usam o google, por considerarem a forma mais rápida de acessar a informação; estudam de forma tradicional, com resumos e leituras, mas agregam alguns recursos da internet como videoaulas; preferem usar material impresso para reduzir o risco de desatenção; não usam a biblioteca escolar e relatam distanciamento entre a biblioteca escolar e a prática docente. Por fim, o artigo apresenta diretrizes para meIhorar a busca e o uso da informação no espaço escolar.
\end{abstract}

Palavras-chave: Ensino Médio. Tecnologias da comunicação e informação. Comportamento Informacional. Letramento Informacional. Busca e uso da informação.

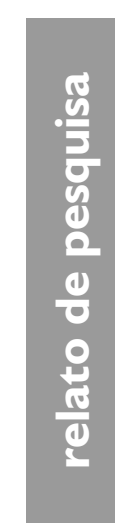

* Doutor em Ciências da Informação pela Universidade de Brasília, Brasil. Professor da Faculdade JK Miquelângelo e coordenador da Revista Acadêmica Eletrônica, Brasil. Professor da Faculdade ICESP Promove - Brasília, Brasil. Professor da Unidesc Centro Universitário, Brasil.

E-mail: anderson.nascimento80@gmail.com.

** Doutora em Ciência da Informação pela Universidade de Brasília, Brasil. Professora Adjunta da Faculdade de Ciência da Informação da Universidade de Brasília, Brasil.

E-mail: kelleycristinegasque@hotmail.com.

\section{INTRODUÇÃO}

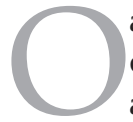
artigo apresenta resultado de pesquisa de doutorado, em que se buscou responder ao questionamento: como ocorrem a busca e o uso de informações por jovens do ensino médio para a formação escolar no contexto das novas tecnologias?. Os objetivos da pesquisa foram conhecer a evolução da juventude na história a partir da contemporaneidade com a influência das novas tecnologias da informação e comunicação no processo de socialização; identificar as principais características que configuram o contexto dos jovens no ensino médio; descrever como as juventudes buscam e usam a informação para a formação acadêmica, considerando as novas tecnologias da informação e comunicação no espaço escolar; avaliar entre os estudantes as propostas de atividades acadêmicas e os sentidos para a construção do conhecimento científico no ensino médio e, por fim, apontar diretrizes para o ensino-aprendizagem, por meio das novas tecnologias em sala de aula, considerando o Letramento Informacional.

A pesquisa é de natureza qualitativa. De acordo com Flick (2005), o método qualitativo considera a pluralidade dos universos de vida. Optou-se pela abordagem denominada método documentário, que considera diversas visões de mundo, em que a função do pesquisador é de acessar o conhecimento implícito do grupo pesquisado, explicitá-lo e definí-lo (WELLER et al, 2002). Para tanto, foram realizados grupos de discussão em três escolas privadas do ensino médio, sendo uma de formação profissional e tecnológica. As três escolas situam-se no Distrito Federal. 
O referencial teórico da pesquisa abrange a relação entre os conceitos de novas tecnologias, juventude, ensino médio, busca e uso da informação e letramento informacional, tratados, brevemente, no próximo tópico. Em seguida, apresentam-se a metodologia, os resultados de pesquisa, as diretrizes de mudanças, e por fim, as conclusões.

\section{REFERENCIAL TEÓRICO}

Este tópico apresenta os principais conceitos adotados na pesquisa e a relação entre eles, com objetivo de compor uma estrutura conceitual. A juventude é compreendida como condição sociocultural (DAYRELL, 2007), situada em um mundo cada vez mais tecnológico, conforme aponta Tapscott (2012) sobre a geração internet. Os jovens precisam lidar com profundas mudanças na socialização e percepção de mundo, o que por sua vez, ocasiona novos desafios às instituições sociais: família, governo, empresas e escolas.

A juventude atual vive em um contexto, em que a vinculação entre a tecnologia, comunicação e informação produz uma massa inigualável de informações. Nesse sentido, a sociedade precisa estar em constante processo de aprendizagem (GASQUE, 2004), o que requer repensar o papel das instituições acadêmicas tradicionais, em especial a do ensino médio. O ensino médio refere-se à terceira etapa de formação da educação básica, posterior ao ensino fundamental, caracterizando-se por três anos no curso regular. Em geral, o estudante inicia o primeiro ano aos 14 ou 15 anos, concluindo a formação básica aos 17 ou 18 anos (BRASIL, 1996).

O ensino médio no Brasil atual encontrase diante de inúmeros desafios, como evasão, desempenho ruim dos estudantes, currículo pouco flexível, crise de finalidade, dentre outros. Há propostas de mudanças, dentre elas, a proposta do Ensino Médio Inovador, sugerida pelo Ministério da Educação (BRASIL, 2013). Tal proposta contempla as diversas áreas de conhecimento a partir do desenvolvimento de atividades nos macrocampos: linguagens matemática, ciências humanas e ciências da natureza. A proposta apresenta oito aspectos a serem apreciados no ensino médio, quais sejam: (1) acompanhamento pedagógico; (2) iniciação científica e pesquisa; (2) leitura e letramento;
(3) línguas estrangeiras; (4) cultura corporal; (5) produção e fruição das artes; (6) comunicação, cultura digital e uso de mídias e, por fim, (7) participação estudantil (BRASIL, 2013).

Não se pode deixar de mencionar a polêmica reforma do ensino médio prevista na Medida Provisória nº 746, em 22 de setembro de 2016. Apesar dos celeumas, algumas recomendações presentes nos Parâmetros Curriculares Nacionais ${ }^{1}$ (PCNs) ainda continuam atuais como a necessidade de o estudante congregar a formação científica com a utilização das diferentes tecnologias relativas às áreas de atuação. Além disso, destacam a importância do aprender a aprender por meio do "[...] desenvolvimento das capacidades de pesquisar, buscar informações, analisá-las, ao invés do simples exercício de memorização" (BRASIL, 2002, p. 12).

$\mathrm{O}$ uso adequado das novas tecnologias, a capacidade de pesquisar e de buscar a informação possibilitam que os indivíduos saibam lidar com a informação para tomar decisões e resolver problemas. De acordo com os PCNs, "o volume de informações, produzido em decorrência das novas tecnologias, é constantemente superado, criando novos parâmetros para a formação dos cidadãos" (BRASIL, 2002 p. 15).

Em suma, as propostas da reforma no ensino médio buscam integrar os estudantes ao mercado de trabalho, bem como dar novo significado a essa fase de ensino, de forma, que eles se sintam mais estimulados e abertos ao conhecimento necessário para viverem melhor na sociedade contemporânea. Apesar disso, observa-se, muitas vezes, uma lacuna entre o que ocorre dentro e fora da sala de aula, isto é, cada vez mais os estudantes estão mais conectados, interativos e iterativos, mas em sala de aula, as aulas ainda são tradicionais e conteúdistas, como afirmam Bacich, Tanzi Neto e Trevisani (2015). Para os autores, as novas tecnologias da informação e comunicação (TIC's) não foram suficientes, ainda, para ocasionar mudanças significativas na metodologia de aula em muitas instituições de ensino. Esse fato corrobora com a perspectiva de não "esperar das redes eletrônicas

\footnotetext{
Os Parâmetros Curriculares Nacionais para o Ensino Médio, de modo geral, auxiliam o professor na execução do trabalho pedagógico, servindo de incentivo e apoio à prática diária. Uma das características dos PCNs do Ensino Médio é a busca pelo significado do conhecimento escolar a partir da contextualização e a interdisciplinaridade (BRASIL, 2002, p. 12).
} 
a solução mágica para modificar profundamente a relação pedagógica" (CABRAL; LEITE, 2008, p. 2). Portanto, a "hiperescola" do futuro apontada por Siqueira (2004), pressupõe que as instituições de ensino sejam capazes de apropriar-se dos recursos tecnológicos com maior eficácia no ensino-aprendizagem.

Dessa forma, os estudos de comportamento informacional podem constituir-se em ferramentas de pesquisas robustas para compreender os estudantes diante das novas tecnologias e o modo como buscam e usam a informação para a formação escolar. O comportamento informacional, de acordo com Wilson (2000), relaciona-se à totalidade do comportamento humano no que concerne às fontes e aos canais de informação. Inclui a busca ativa e passiva da busca de informação e o uso da informação, abrangendo, por exemplo, comunicação face a face, comunicação com outros, recepção ativa da informação, dentre outros.

A busca da informação constitui-se um aspecto do comportamento informacional, resultante do ato de satisfazer uma necessidade de informação. Nesse processo, o indivíduo pode interagir com sistemas de informações analógicos ou eletrônicos. Por sua vez, a pesquisa de informação refere-se ao nível mais restrito da busca de informação. Consiste, especificamente, na interação humana com os sistemas computadorizados, por exemplo, adoção de estratégias com uso de operadores booleanos (WILSON, 2000).

O uso da informação, por sua vez, o abrange os atos físicos e mentais necessários à aquisição da informação ao arcabouço cognitivo. Wilson (2000) exemplifica que a marcação de texto, comparações entre informações podem ser compreendidos, respectivamente, como atos físicos e mentais do uso da informação.

A presente pesquisa considera que a busca, a pesquisa e o uso da informação não são atividades excludentes e, podem ocorrer, simultaneamente. Reconhece-se, também, que os estudos de comportamento informacional centram-se no usuário e na necessidade de informação, que decorre dos vários contextos em que o sujeito se insere. Pretende, portanto, conhecer o processo de busca e uso da informação entre os jovens do ensino médio a partir das necessidades surgidas no contexto escolar atual, considerando as múltiplas disciplinas e os desafios que compõem a respectiva etapa.
Parte do pressuposto que os estudantes do ensino médio usam as novas tecnologias para buscar informações acadêmicas, muitas vezes, sem a formação adequada. O fato de serem nativos digitais não o tornam competentes em lidar com a informação. Ao contrário, muitas vezes, buscam e usam a informação de forma pouco sistematizada, sem terem critérios de como selecionar informações confiáveis (GASQUE, 2012).

Mesmo considerando que vários fatores influenciam o comportamento informacional como, por exemplo, a formação básica do usuário; treinamento para o uso de serviços e produtos; acessibilidade das unidades da informação; condições de trabalho; status hierárquico do indivíduo; dentre outros (GASQUE, 2008), pode haver melhoria significativa ao integrar o letramento informacional no meio acadêmico. O letramento informacional constitui-se em processo de aprendizagem voltado ao desenvolvimento de competências, no intuito de localizar, selecionar, acessar, organizar, usar informação e, assim, construir o conhecimento. Tal processo implica, portanto, um processo contínuo, vinculado à vida e ao contexto social (GASQUE, 2012).

\section{METODOLOGIA DE PESQUISA}

A pesquisa possui natureza qualitativa e foi realizada com grupos de discussão em três escolas privadas de ensino médio do Distrito Federal, nomeadamente, Colégio JK, situado no Gama - DF; Colégio Marista Champagnat, de Taguatinga -DF e Escola Sesi (Serviço Social da Indústria, do Gama - DF. Cada grupo contou com a participação de seis estudantes, escolhidos de acordo com os critérios:

- Estudante com frequência escolar regular no ensino médio.

- Possui celular e acesso à internet.

- Com hábito diário de utilizar as tecnologias da informação e comunicação.

- Uso de tecnologias durante as aulas ou realização de tarefas escolares.

- Possíveis registros de indisciplina devido ao uso de tecnologias na escola.

Para a realização dos grupos de discussão, utilizou-se o Modelo do tópico-guia, considerando o objetivo geral e os objetivos específicos da pesquisa, como se pode observar no quadro 1. 
Quadro 1 - Modelo do tópico-guia usado na discussão de grupo

Objetivo geral: Analisar como os/as jovens inscritos no ensino médio buscam e usam a informação por meio das novas tecnologias para a formação escolar.

\section{Objetivo específico:}

Conhecer a evolução da juventude na história, principalmente a partir da contemporaneidade com os impactos das novas tecnologias da informação e comunicação no processo de socialização.

\section{Objetivo específico:}

Identificar as principais características que configuram o contexto dos jovens no ensino médio.

- Qual importância da internet em suas vidas?

\section{Objetivo específico:}

Descrever como a juventude busca e usa informação para a formação acadêmica, considerando as novas tecnologias da informação e comunicação no espaço escolar.

\section{Objetivo específico:}

Avaliar entre os estudantes as propostas de atividades acadêmicas e seus sentidos para a construção do conhecimento científico no ensino médio.

- Quais as percepções sobre a escola atual?

- O que pensam sobre o ensino médio?

- A escola motiva o uso de recursos tecnológicos para a pesquisa escolar?

- Em quais fontes de informação buscam a informação necessária para pesquisas?

- Como vocês buscam a informação na internet para as atividades acadêmicas? - Qual a importância da confiabilidade da informação?

- Como vocês estudam?

- Como é realizada a leitura dos textos escolares?

- Faz diferença na aprendizagem lidar com material impresso ou digital?

- Como vocês avaliam as propostas de atividades no ensino médio para a aprendizagem/conhecimento?

\section{Objetivo específico:}

Elaborar diretrizes de implementação do letramento informacional, considerando as especificidades do ensino médio privado em três escolas do Distrito Federal.

\section{Fonte: elaboração própria}

Os grupos de discussão foram analisados por meio do método documentário. Compreende-se o método documentário como método interpretativo de pesquisa que considera diversas visões de mundo, de acordo com artigo de Mannheim, publicado em 1922 (WELLER et al, 2002). Bohnsack e Weller (2011) explicam que Mannheim (1922) conceituou as visões de mundo a partir das ações práticas, definidas por ele como conhecimento ateórico, uma vez que "a compreensão das visões de mundo e das orientações coletivas de um grupo só é possível por meio da explicação e da conceituação teórica desse conhe- cimento ateórico" (p. 68). Ainda, segundo Mannheim (1922), o processo de interpretação possui três níveis, quais sejam:

(1) Nível objetivo ou imanente - dado naturalmente (por exemplo, num gesto, num símbolo ou ainda na forma de uma obra de arte);

(2) Nível expressivo - transmitido por meio das palavras ou das ações (por exemplo, como expressão de ou como reação a algo);

(3) Nível documentário, ou seja, como documento de uma ação prática (BOHNSACK; WELLER, 2011, p. 69). 
Os três níveis possibilitam, durante o processo metodológico, conhecer o cotidiano dos indivíduos em estudo, tanto no contexto social quanto em relação às ações individuais e coletivas. Bohnsack (2007), adaptou, de certa forma, o método documentário para a análise de grupos de discussão, com intuito de transcender o nível de análise intuitivo ou dedutivo. O método desenvolvido estrutura-se a partir de quatro etapas distintas.

A primeira consiste na organização temática, que exige do pesquisador, após a realização da entrevista ao grupo, um relatório com as informações relacionadas ao contato inicial com o grupo, ou seja, como ele foi selecionado e em que local. A segunda etapa abrange a interpretação formulada. Diz respeito a interpretação do sentido imanente das discussões, decodificando-as do vocabulário coloquial. A terceira etapa, definida como interpretação refletida, busca analisar o conteúdo, as ações do indivíduo ou grupo pesquisado, bem como as motivações que permeiam as ações. A quarta etapa é apresentada como análise comparativa entre os resultados dos grupos de discussão. Por fim, a quinta etapa é a construção de tipos e análise multidimensional, que diz respeito a um modelo de orientação que se repete ou a diferentes modelos de orientação ou estratégias de enfrentamento de uma determinada situação (BOHNSACK; WELLER, 2011).

Após a realização dos grupos de discussão, seguidos de um roteiro tópico-guia, houve a transcrição da entrevista, com o uso dos códigos conforme o modelo em anexo elaborado por Weller (2006). Em seguida, foi feita a separação por temas, de modo a possibilitar a análise dos conteúdos nos distintos grupos de discussão.

As mesmas questões previstas no roteiro tópico-guia foram aplicadas aos três grupos de discussão nas diferentes escolas particulares do ensino médio. Os grupos foram realizados após a entrega das cartas de solicitação da pesquisa de campo, já autorizadas, contendo os nomes das instituições e também as cartas de autorização e os termos de compromissos com os dados a serem coletados entre os estudantes do ensino médio particular. Desse modo, não houve a identificação, na produção escrita, do nome dos estudantes, os quais tiveram o nome codificado. Com dos dados transcritos, iniciou-se a análise dos grupos.

\section{ANÁLISE DOS GRUPOS DE DISCUSSÃO}

A análise dos grupos de discussão envolve a interpretação formulada e a interpretação refletida dos grupos de discussão das escolas pesquisadas no segmento do ensino médio. A interpretação formulada é a parte em que o pesquisador descreve o que foi dito pelos participantes dos grupos, apontando o conteúdo das falas por meio de uma linguagem compreensível aos indivíduos que não pertencem ao meio social pesquisado. Contudo, pela questão do espaço, optou-se por apresentar somente a interpretação refletida, por ser mais abrangente, pois além de expor os dados da interpretação formulada, mostra a análise comparativa dos grupos.

\section{I Interpretação refletida e análise comparativa dos grupos de discussão}

A etapa de interpretação refletida busca analisar 'padrões homólogos ou aspectos típicos do meio social'. Para tanto, é fundamental a comparação com outro grupo, "uma vez que o modelo de orientação de um determinado grupo só pode ser constatado quando colocado em relação a outros horizontes ou universos comparativos de outros grupos" (BOHNSACK; WELLER, 2011, p. 82).

A importância da internet, da escola atual, do ensino médio e do uso de recursos tecnológicos para a pesquisa escolar.

Os grupos de discussão foram iniciados com questões preliminares, voltadas para a juventude na contemporaneidade, fortemente caracterizada pelo uso das novas tecnologias da informação e comunicação. Os relatos dos estudantes mostram que a internet possibilita ampliar as informações obtidas na escola. Para eles, a internet é importante não apenas para o entretenimento, mas também para os estudos.

Por outro lado, observou-se que a visão dos estudantes é reducionista em relação aos problemas gerados pela internet, como, por exemplo: o desemprego; a queda na compra de jornais e revistas com escritores 
renomados; a redução de vendas de DVDs e, consequentemente, a pouca produção de qualidade de filmes, musicais e documentários a partir da ascensão do Youtube; a crise de editoras, gravadoras e estúdios no cenário nacional e internacional; o crescimento desenfreado da pirataria; o plágio e o crescimento irrefreável do Google (KEEN, 2009).

Os jovens da sociedade contemporânea são denominados "geração zapping", ou seja, aquela que vive mudando de canal o tempo todo. Além disso, o uso simultâneo dos recursos e aplicativos da internet também abrange, inclusive, tarefas que exigem concentração, principalmente nos estudos (ALMEIDA; EUGÊNIO, 2006). Neste sentido, os jovens ressaltaram a preocupação com o entretenimento propiciado pela internet no ato de estudar, por exemplo, as redes sociais, jogos on-line, entre outros.

De certo modo, a nomofobia ${ }^{2}$ atinge o público juvenil de forma massiva, e chega a ocasionar questões de indisciplina, ou até dificuldades na aprendizagem, pois muitos estudantes não conseguem desconectar da rede. As consequências de viver o tempo todo on-line nem sempre são satisfatórias. Jovens que não dormem o tempo necessário para o descanso comprometem a aprendizagem, pois ficam sonolentos durante as aulas, sem qualquer disposição para aprendizagem. Por isso, Turkle (2011) mostra preocupação com a geração digital ao descrever que muitos jovens buscam nos computadores e dispositivos o preenchimento da ausência dos pais, e acabam por descobrir sua identidade imerso no ciberespaço.

No que se refere às percepções dos estudantes sobre a escola atual, especificamente a realidade do ensino médio, os discursos mostram convergências, como, por exemplo, o ensino médio como preparação para o vestibular. $\mathrm{O}$ relato dos estudantes entrevistados mostra uma visão de ensino médio voltada ao 'treinamento' para uma prova no final do ano. Isso contraria a perspectiva de um segmento de ensino que possibilite ao estudante "identificar, compreender e buscar suprir, ao longo de sua vida, suas necessidades com relação à participação na produção científica, tecnológica e cultural" (KUENZER, 2009, p.43).

2 No + Mobile + Phobia, ou seja, fobia de permanecer sem os dispositivos móveis.
Outro aspecto levantado pelos estudantes foi o excesso de disciplinas e aulas, muitas vezes desnecessárias. Em uma das escolas pesquisadas, foi criado, em 2016, o sétimo horário no período matutino, tornando a manhã ainda mais cansativa, com excesso de informações em apenas um período de aula. Sobre isso, o Programa Ensino Médio Inovador (2013) apresenta-se como subsídio para discussão com objetivo de integrar os componentes curriculares de cada área de conhecimento e entre áreas, "pois o problema principal não se apresenta pela quantidade de disciplinas, mas pelo excesso e pela sobreposição de conteúdos desarticulados no currículo da escola" (GARCIA, 2014, p. 56).

O Programa do Ensino Médio Inovador, segundo Garcia (2014), consiste em melhorar as aulas e ultrapassar os conteúdos definidos somente pelos livros didáticos e pelas avaliações externas. É preciso, nessa etapa de formação, propiciar aos jovens estudantes o protagonismo no ato de estudar e o sentido dos conteúdos estudados. Além disso, Demo (1996) enfatiza a relevância de o professor exercitar a prática da pesquisa, trabalhando-a, sempre que possível, em sala de aula, de modo a tornar a escola um espaço privilegiado de construção do conhecimento.

Sobre a escola atual e o uso de recursos tecnológicos no processo ensino-aprendizagem, os estudantes reconhecem que as instituições de ensino estão atentas às mudanças, adaptandose ao uso de plataformas virtuais, aparelhos data show em salas de aula e salas próprias para usar as tecnologias: internet, música, televisão, computadores etc. Tais percepções confirmam o ingresso, mesmo que incipiente, das novas tecnologias da informação e comunicação no espaço educacional, pois "o fluxo de interações nas redes e a construção, a troca e o uso colaborativos de informações mostram a necessidade de construção de novas estruturas educacionais" (KENSKY, 2007, p. 48).

Pesquisa recente mostra que " $80 \%$ dos jovens usam computadores e internet e $89 \%$ têm aparelho celular" (FREITAS; FRANÇA; ALVES, 2015, p.194). Embora os estudantes usem os recursos tecnológicos cotidianamente, nem sempre o fazem da melhor maneira, pois muitos não aprenderam buscar informações confiáveis para as necessidades escolares.

Morrissey (2012) aponta dois desafios interdependentes na educação do século XXI. 
O primeiro consiste em demonstrar claramente o valor educativo das TIC's na sala de aula. O segundo implica no convencimento das instituições de educação em proporcionar altos níveis de investimento necessários para se conseguir chegar a uma mudança real na educação por meio do uso das TIC's.

Para realizar a integração das TIC's nas escolas é preciso, de acordo com Morrissey (2012, p. 271): (1) provisão de recursos suficientes em TIC's, confiáveis, de fácil acesso e disponíveis aos docentes e estudantes; (2) inclusão das TIC's no desenvolvimento do currículo e na posterior implementação; (3) uso das TIC's deve refletir na forma avaliação dos estudantes, (4) formação contínua baseada em TIC's para os docentes; (5) apoio para diretores e coordenadores de TIC's nas escolas para dominar o uso e facilitar a aprendizagem entre os colegas e o intercâmbio de recursos (6) provisão de recursos digitais de alta qualidade, materiais de ensino e exemplos de boas práticas para envolver os estudantes e apoiar os docentes.

\section{A busca de informação entre jovens no contexto escolar.}

Neste segundo bloco, os grupos de discussão trataram da busca de informação no espaço escolar. Ou seja, a busca de informação voltada para as pesquisas realizadas na escola, principalmente sobre a confiabilidade das informações adquiridas pela internet.

Os estudantes relataram ter preocupação em buscar informações de forma mais rápida, sem se preocupar muito com a origem da informação. Para tanto, o recurso mais citado foi o Google comum e relataram usar, às vezes, a Wikipédia. Ressaltaram as contribuições do Youtube, por favorecer revisões através de videoaulas, bem como relataram o uso de sites como a Escola Brasil. Por sua vez, o Yahoo como fonte de pesquisa foi desqualificado pelos estudantes. O uso da plataforma virtual foi mencionado por estudantes de duas escolas, constituindo-se uma ferramenta de busca da informação para realização de atividades propostas pela escola.

A busca de informações entre estudantes e professores não ocorre de maneira muito diferente, como mostra a pesquisa realizada com professores da educação básica. As autoras da pesquisa concluem que os docentes efetuavam buscas em fontes e canais de informações mais próximos, não se preocupando muito com a qualidade da informação no planejamento das aulas (GASQUE; COSTA, 2003).

Em relação às plataformas de aprendizagem, esses recursos criam novas oportunidades para os professores compartilharem com os estudantes o acesso às informações e trabalharem de forma cooperativa. Contudo, no cenário acadêmico, torna-se necessário avaliar, detalhadamente, o uso da plataforma virtual como recurso no processo de ensino-aprendizagem, pois "quando se decide pela utilização de um AVA é preciso estabelecer critérios coerentes que sejam mais adequados ao processo educacional" (FRANCISCATO et al., 2008, p .2).

Destaca-se a importância dos ambientes virtuais de aprendizagem possuírem estrutura fácil e interativa. O material disponibilizado deve ser diferenciado para propiciar novas formas de aprender (MUNHOZ, 2011), o que nem sempre ocorre dentro das escolas, no dizer dos estudantes entrevistados.

Apesar de os estudantes citarem o google como recurso de pesquisa, não conhecem todas as potencialidades que ele propicia ao usuário. O Google Acadêmico, por exemplo, foi mencionado somente uma vez, por um grupo de uma escola. Vale ressaltar que nesta escola existe um projeto voltado à iniciação científica nas três séries do ensino médio - projeto Mostra de Iniciação Científica (MIC) - com aulas destinadas à orientação, à seleção de textos, à elaboração de problemas e objetivos. Além do projeto Mostra de Iniciação Científica (MIC), os docentes, ao corrigirem os trabalhos solicitados, desconsideram os textos que utilizam cópia da internet sem a devida referência.

De modo geral, os estudantes parecem desconhecer sites confiáveis de busca da informação. Em momento algum citaram as bibliotecas on-lines, nem outros sites de cunho científico mais conhecido.

Em relação à busca da informação, ressalta-se que estudos recentes apontam avanços no processo ensino-aprendizagem de estudantes com a implementação do Letramento Informacional no espaço escolar. "Percebeu-se que o processo de aprendizagem dos estudantes 
no que concerne ao comportamento foi alterado positivamente" (MACEDO, 2015, p.179). Houve superação de dificuldades, mais segurança e autonomia no processo de pesquisa.

O próximo tópico trata da forma como os jovens estudam e lêem os textos acadêmicos para as atividades da escola. Além da avaliação das atividades de ensino-aprendizagem propostas no ensino médio.

\section{O estudo e a proposta de atividades de ensino- aprendizagem no ensino médio}

A questão sobre o modo como os jovens estudam no ensino médio mostra que as atividades de estudos não se diferenciam muito das tradicionais. No Colégio JK, por exemplo, os estudantes fazem revisão a partir do conteúdo ministrado em sala de aula e aproveitam as tarefas para compreenderem melhor os conceitos abordados. Há também a opção por resumos no caderno após pesquisas na internet, ou ainda os 'tarefões' - projeto semanal que permite aos docentes postar atividades sobre as aulas da semana. Na escola do SESI, alguns estudantes relataram estudar em vésperas de provas, enquanto no Colégio Marista o uso de videoaulas é um recurso comum ao grupo, ainda que recorram à internet somente em vésperas de prova. Isso parece corroborar a ideia de que, muitas vezes, a aprendizagem desenvolve-se de forma fragmentada no espaço escolarizado, com resumos substituindo a leitura de livros, em um tempo cada vez mais imediatista (LEVINE, 1997).

Os dados obtidos nos grupos entrevistados mostram as dificuldades dos estudantes em manterem a atenção nas leituras exigidas pela escola. De acordo com eles, as leituras precisam ser retomadas várias vezes. Quando o material didático não é suficientemente claro nas explicações dos conteúdos, os estudantes recorrem à internet para buscar leituras capazes de complementar a matéria. Contudo, as atividades de buscas de informação na internet não são sistematizadas e criteriosas.

Com relação à preferência pela leitura em material impresso ou digital, prevaleceu a leitura do texto impresso. A leitura digital, dadas as possibilidades de entretenimento no computador ou celular, ocasiona maior distração e compromete a compreensão do texto lido. Por isso, vale ressaltar a necessidade de cuidados voltados à utilização das tecnologias, de forma efetiva, para que as distrações não virem armadilhas (BAUMAN, 2013).

Isso parece contradizer os estudos de Moran, Massetto e Behrens (2000, p.21) ao afirmar que os "jovens estão totalmente sintonizados com a multimídia, que quando lidam com texto fazemno mais facilmente com o texto conectado através de links, de palavras-chave, o hipertexto". Nesse contexto, o desafio do educador atual consiste em tornar a informação significativa. Isto é, "escolher as informações verdadeiramente importantes entre tantas possibilidades, a compreendê-las de forma cada vez mais abrangente e profunda e a torná-las parte do nosso referencial" (MORAN; MASSETTO; BEHRENS, 2000, p.23).

Para finalizar o tópico, os estudantes discutiram sobre as atividades propostas pela escola. As percepções dos estudantes pesquisados apresentam convergências, por exemplo, sobre: a justificativa da nota imposta pelos docentes; a preparação para o vestibular; a memorização do conteúdo a partir dos exercícios; as tarefas pouco significativas e a quantidade de disciplinas.

\section{Percepção dos estudantes sobre a biblioteca da escola}

A última questão apresentada aos grupos de discussão gerou dados relevantes para refletir sobre a finalidade da biblioteca escolar na contemporaneidade. Campello (1998) argumentava que a ação do bibliotecário nas escolas era frágil. Mesmo passados quase duas décadas, não houve mudança expressiva nas instituições de ensino sobre o papel do bibliotecário e a própria estrutura das bibliotecas existentes nas escolas, especificamente no segmento do ensino médio, segundo relatos dos estudantes.

A pouca frequência dos estudantes nas bibliotecas escolares é um sintoma a ser questionado pelos pais, docentes e gestores das instituições educacionais. $\mathrm{O}$ ato de educar consiste no trabalho colaborativo entre professores e bibliotecários (FIALHO, 2004), de forma que a biblioteca esteja vinculada à sala de aula e faça parte da rotina escolar dos estudantes. Por isso, vale destacar o papel da 
biblioteca escolar e a responsabilidade da direção pedagógica em todo o processo da formação dos estudantes (TOOD; KUHLTHAU, 2003).

Os dados das escolas pesquisadas revelam o paradoxo entre o que é previsto na proposta educativa das diferentes instituições e o que realmente ocorre na prática. Os estudantes do primeiro grupo entrevistado disseram que a biblioteca não é adequada, alegando que os livros existentes não contribuem com os estudos no ensino médio.

O paradoxo existe porque nas três escolas há forte preocupação com a preparação para o vestibular. No entanto, nenhum grupo apontou a biblioteca como espaço favorável para o estudo e a pesquisa. Para agravar a situação de visitação estudantil no referido espaço, uma biblioteca de um dos colégios criou um critério que mais dificulta do que motiva a frequência dos estudantes no local: para pegarem um livro, os estudantes precisam doar outro; quem não doar, não pode levar emprestado outro livro do acervo para ler em casa. Na verdade, a escola passa para o estudante o ônus de investir no acervo da biblioteca escolar.

No SESI, alguns estudantes afirmaram que a instituição não comprou livros sugeridos à biblioteca, em anos anteriores. Nem todos os estudantes entrevistados conheciam a bibliotecária, mesmo com a existência de um projeto de leitura na educação infantil e no ensino fundamental, conforme disseram, sem continuidade no ensino médio. Tais afirmações dos jovens contrariam o reconhecimento da importância da biblioteca no contexto escolar frente às exigências do currículo e o incentivo ao hábito da leitura, assim como o desenvolvimento da capacidade de pesquisar (PERUCCHI, 1999).

Embora existam duas bibliotecas no colégio Marista, os estudantes participantes do grupo de discussão não as frequentam devido ao barulho externo, pelo fato de ser localizada em frente ao pátio, onde as crianças e adolescentes brincam. Além disso, mesmo os que estudam há mais tempo na escola, não conhecem a bibliotecária. Esses fatos vão de encontro ao estudo de Gasque e Casarin (2016, p.9) ao apresentar tendências globais das bibliotecas escolares:

Esse espaço deveria ter a flexibilidade necessária para ser utilizado por

\begin{abstract}
diferentes professores e classes; espaços para tarefas de aprendizagem em grupos baseadas em projetos e atividades multimídia; áreas para contação de histórias, apresentações ou performances; áreas para leituras ou estudo individuais e outros espaços adaptados para estudantes com necessidades especiais. (GASQUE; GESARIN, 2016, p.9)
\end{abstract}

É imprescindível para as escolas, a compreensão de como deve ser a biblioteca na atualidade, principalmente com as transformações no processo de ensinoaprendizagem e o impacto das tecnologias nas bibliotecas. Sobre essa questão, vale destacar novamente o estudo das tendências globais em bibliotecas escolares.

De acordo com Gasque e Casarin (2016), as escolas devem investir em um modelo mais conectado e colaborativo no processo ensino-aprendizagem. Isso significa repensar a forma como as escolas funcionam, com reforço no envolvimento dos estudantes em um ensino interdisciplinar e globalizante; utilização de abordagens de aprendizagens colaborativas através das ferramentas digitais; elaboração de projetos em equipe; estimulo desenvolvimento de competências para buscar e usar a informação no ambiente digital; currículo orientado para a investigação e reflexão (independente e colaborativa); acesso a conteúdos por meio de dispositivos móveis, com aquisição de conteúdo digital e de acordo com o nível acadêmico (com colaborações entre bibliotecas); atualização do espaço com novo design da biblioteca escolar, mais flexível e voltado à partilha e produção do conhecimento; além do reconhecimento do novo papel do bibliotecário como função pedagógica. Por isso, a biblioteca escolar contemporânea deve atuar como centro de recursos de aprendizagem (GASQUE; CASARIN, 2016).

Contudo, no Brasil, há mais de duas décadas, Antunes (1993) apontou uma preocupação persistente nos dias atuais ao afirmar em estudos que, dada a amplitude da rede escolar no Brasil, praticamente 99\% das escolas brasileiras fechariam as portas se a existência de bibliotecas fosse condição sine qua non para o funcionamento. Essa observação é válida para as escolas pesquisadas. 


\subsection{Resumo dos dados coletados}

Os resultados apresentados na figura 1, a seguir, mostram um resumo genérico dos dados coletados na pesquisa. O contexto contemporâneo em que a escola se insere, de maneira geral, usa intensivamente as tecnologias da comunicação e informação. Contudo, a escola precisa investir mais em recursos em quantidade suficientes para os estudantes, formação de professores, processo de letramento informacional, currículo mais flexível, dentre outros aspectos. Os estudantes percebem o currículo no ensino médio como preparação para o vestibular/ENEM, com ensino-aprendizagem tradicional, aulas expositivas e sem favorecer a interação. Os estudantes, ao necessitar de informações, preferem aquelas de fácil acesso e, usam, predominantemente, o Google como buscador. Os estudantes relatam ressalvas com o yahoo. As plataformas virtuais, Wikipédia e Brasil escola, são recursos de busca da informação citados pelos estudante para pesquisa. As redes sociais - Youtube, Skype, What's app e Facebook - são utilizadas para o estudo e a socialização. Os recursos tecnológicos mais utilizados são Ipad, computador e celular. Por fim, a biblioteca escolar se encontra distante da rotina estudantil, com acervo limitado e desatualizado, ausência de projetos e total desconhecimento do papel do bibliotecário pelos estudantes.

Figura 1 - Síntese dos principais dados coletados

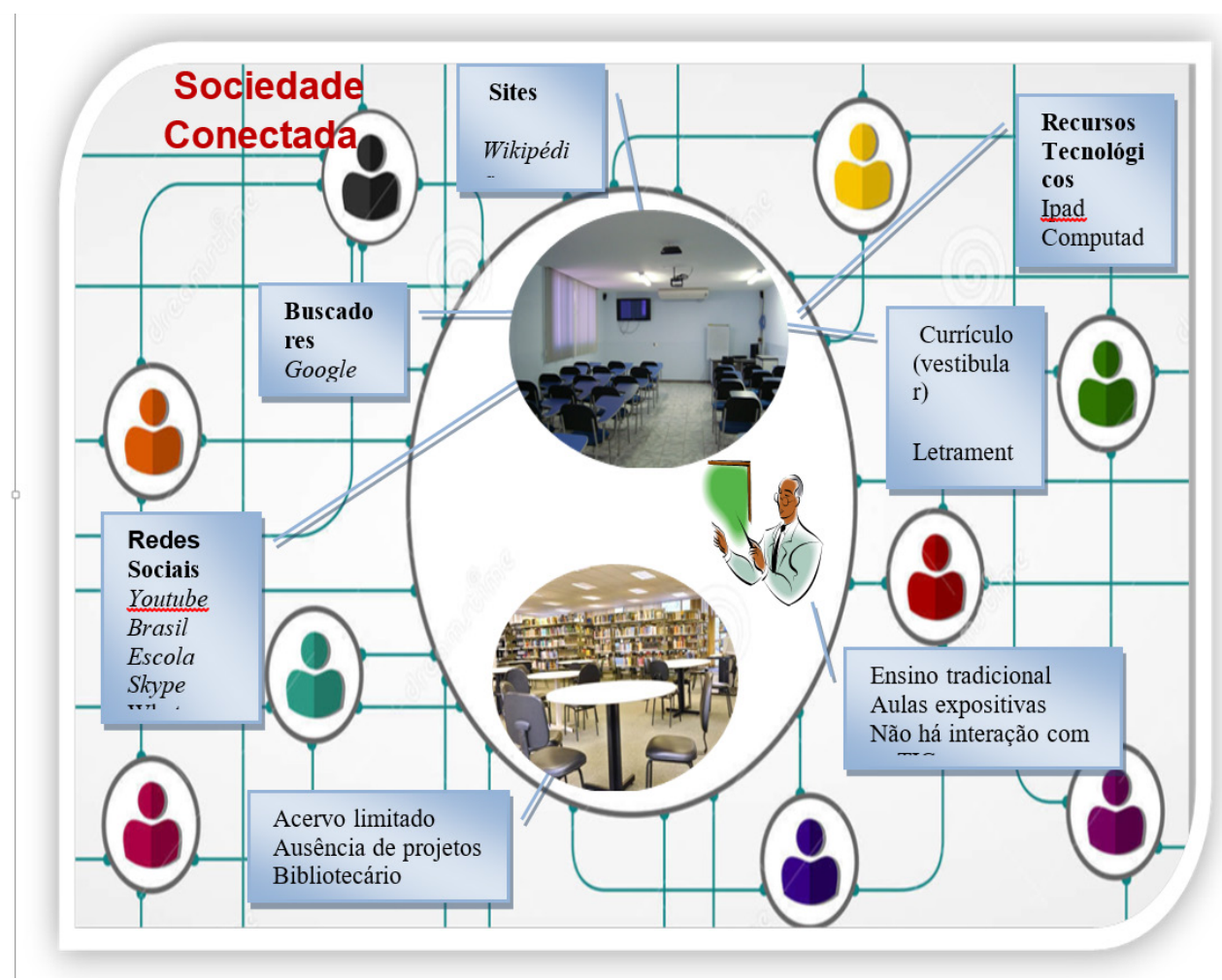

Fonte: elaboração própria

\section{DIRETRIZES PARA O ENSINO MÉDIO}

As diretrizes foram elaboradas, considerando os resultados apresentados, bem como a revisão de literatura realizada nessa pesquisa. Entende-se por diretrizes orientações e metas com objetivo de alcançar melhor desempenho. São elas:

- Repensar a concepção pedagógica da escola, com adoção de abordagens de aprendizagens que sejam mais 
significativas, contextualizadas e voltadas para resolução de problemas.

- Revisar a quantidade e a qualidade dos conteúdos curriculares do ensino médio.

- Implementar o letramento informacional considerando as melhores práticas sugeridas pela Association of College and Research Libraries (ACRL, c 1996-2017), que recomenda, a integração entre os itens: 1) missão 2) metas e objetivos; 3) planejamento; 4) apoio administrativo e institucional; 5) sequência adequada do programa no currículo; 6) colaboração de toda a comunidade; 7) concepção pedagógica apropriada, 8) pessoal com formação e em quantidade suficiente; 9) divulgação do projeto e resultados; e, por fim, avaliação do processo e das pessoas e dos resultados.

- Considerar os conteúdos sugeridos por Gasque (2012), quais sejam:

1) iniciação básica à filosofia da ciência; 2) conceito e a importância do planejamento e método para resolução dos problemas; 3) organização/arranjo das várias fontes de informação impressas e on-line; 4) utilização das novas tecnologias como recursos de busca e disseminação do conhecimento; 5) busca de informações na internet de maneira eficaz e eficiente; 6) avaliação dos canais e fontes de informação; 6) seleção, organização dos dados, relação entre os pontos de vista e síntese das ideias; 7) leitura e compreensão de diversos tipos de textos; 8) produção de textos científicos, resumos, esquemas e sínteses, 9) normas da ABNT para apresentação de trabalhos; 10) autoria e plágio; 11) organização das bibliotecas e uso dos recursos e produtos disponíveis 12) produção das obras - do planejamento à distribuição no mercado.

\section{CONCLUSÕES}

A presente pesquisa insere-se nos estudos do comportamento informacional, área que analisa as ações dos indivíduos na busca, uso e transferência de informação a partir das necessidades que emergem dos vários contextos - social, político, educacional, econômico
(WILSON, 2000). A pesquisa analisou a busca e o uso de informações, por meio das novas tecnologias, por jovens do ensino médio para a formação escolar. Observa-se a necessidade de cada vez mais lidar com a multiplicidade e quantidade de informações produzidas na sociedade contemporânea.

A realidade do ensino médio nas escolas pesquisadas é comprometida com a competitividade dos exames de vestibular (PAS) e (ENEM). O ensino-aprendizagem é centrado no 'treinamento' para realização da prova, memorização de conteúdos, tarefas pouco significativas e descontextualizadas, bem como grande quantidade de disciplinas.

Os resultados mostram que as escolas preocupam-se em adaptar as salas de aula às novas tecnologias, mas sem capacitação docente capaz de proporcionar práticas de ensinoaprendizagem inovadoras e eficazes. Além disso, o uso das novas tecnologias ocorre de maneira pouco sistematizada e sem funcionalidade clara. Não são conteúdos integrados ao currículo.

Nas escolas pesquisadas, os estudantes não são estimulados a frequentar a biblioteca escolar, pois as escolas não ensinam a pesquisar e não incentivam a aprendizagem autônoma. Por sua vez, as bibliotecas apresentam estrutura aquém das necessidades dos estudantes, com acervo limitado, desatualizado e não informatizado. Estes espaços são tradicionais, com poucos investimentos e não funcionam como Centro de Recursos de Aprendizagem.

Nesse contexto, não há espaço para o aprender a aprender, ou seja, os estudantes não são letrados informacionalmente. Eles utilizam recursos simples de busca, com foco na facilidade de acesso. Apesar de usarem com frequência o google, eles não conhecem todas as funcionalidades do sistema. Também no que concerne aos estudos, conhecem as estratégias básicas como resumo, leitura, e às vezes, uso de videoaulas, por exemplo. Nesse contexto , a formação de professores voltada para a compreensão e aplicação dos conteúdos de letramento informacional torna-se essencial. Estes conteúdos abrangem a seleção, busca e uso da informação, além da comunicação da informação considerando os aspectos éticos, legais e econômicos.

Contudo, não basta somente integrar os conteúdos de Letramento informacional no 
programa. É preciso que ele faça parte da missão da instituição, permeando metas e objetivos. Além disso, é preciso que haja planejamento para inserir o letramento informacional, com o apoio administrativo e institucional. Outro ponto importante diz respeito à sequência dos conteúdos no currículo, que por sua vez, relaciona-se com a concepção pedagógica da instituição e a colaboração da comunidade na construção curricular. Nesse sentido, a formação de professores, funcionários torna-se fundamental. Deve ser realizada com a mesma metodologia a ser usada pelos estudantes. A criação de espaços de comunicação para informação da comunidade também é necessária para engajamento da comunidade.

Conclui-se que a formação de estudantes para a pesquisa, com diversos recursos disponíveis nas bibliotecas e na internet, dependerá da mudança de mentalidade das escolas quanto ao entendimento da função das bibliotecas em todos os segmentos da educação, principalmente no ensino médio, pois os jovens estudantes se encontram diante de tomada de decisões que repercutirão no futuro de suas vidas.

Os pressupostos de um ensino médio voltado para a formação humana, ética e cidadã, capaz de preparar os sujeitos para a vida, não apenas treinando-os para avaliações de vestibular, contribuirão significativamente com a sociedade, pois, antes mesmo de ingressarem no ensino superior, os estudantes aprenderão a pesquisar e a produzir o conhecimento científico de forma crítica e autônoma.

Artigo recebido em 05/06/2017 e aceito para publicação em 19/10/2017

\section{NEW TECHNOLOGIES, THE SEARCH AND USE OF INFORMATION IN HIGH SCHOOL}

ABSTRACT This article is the result of a doctoral research on how young people in high school search and use information through the new technologies in school education. The research is of a qualitative nature, conducting discussion groups in three private high schools, being one of them a professional and technological education institution of the Federal District. The documentary method gave support to the analysis of the discussion groups. Results show that students perceive high school as "training" for the university entrance examination. Schools do not develop strategies for teaching how to search and use information. Students use Google because they consider it the fastest way to get access to information. They study, in a traditional way, through readings and summaries, but include some internet resources such as video classes. They prefer to use printed material to cut the risk of inattention. Do not use the school library and point to a distancing between the school library and the teaching practice. Finally, the article presents guidelines to improve the search and use of information in the school environment.

Keywords: High School. Information and Communication Technologies. Information Behavior. Information Literacy. Search and use of information.

\section{REFERENCIAS}

ALMEIDA, I. M. de; EUGENIO, F. O espaço real e o acúmulo que significa: uma nova gramática para se pensar o uso do jovem da internet no Brasil. In: Nicolaci da Costa, A. M. Cabeças digitais: o cotidiano na era da informação. Rio de Janeiro: PUC-Rio; São Paulo: Loyola, 2006. p.4756.
ANTUNES, W. A. Bibliotecas escolares: curso de capacitação do professor regente de biblioteca. Brasília: CORBI, 1993.

ASSOCIATION OF COLLEGE AND RESEARCH LIBRARIES. Characteristics of Programs of Information Literacy that Illustrate Best Practices: a guideline. Disponível em: < http://www.ala.org/acrl/ standards/characteristics>. Acesso em: 17 fev. 2017. 
BACICH, L.; TANZI NETO, A.; TREVISANI, F. M. (Org.). Ensino híbrido: personalização e tecnologia na educação. Porto Alegre: Penso, 2015.

BAUMAN, Z. Sobre educação e juventude. Rio de Janeiro: Zahar, 2013.

BOHNSACK, R.; WELLER, W. O método documentário na análise de grupos de discussão. In: W. W.; N. P. (Org.). Metodologias da pesquisa qualitativa em educação: teoria e prática. 2. ed. Petrópolis: Vozes, 2011. p. 67-86.

BRASIL. Ministério da Educação. Secretaria de Educação Básica. Programa Ensino Médio Inovador: documento orientador. Brasília: MEC, 2013.

.Ministério da Educação. Secretaria de Educação Média e Tecnológica. Parâmetros Curriculares Nacionais. Brasília: MEC, 2002.

.Lei $\mathrm{n}^{\circ}$ 9.394, de 20 de dezembro de 1996. Disponível em: <http://www.planalto.gov.br/ CCIVIL_03/leis/L9394.htm>. Acesso em: $17 \mathrm{fev}$. 2017

CABRAL, G. R.; LEITE, 1. S. O uso de sites educativos na prática docente. In: ENCONTRO DE EDUCAÇÃO E TECNOLOGIAS DE INFORMAÇÃO E COMUNICAÇÃO (E-TIC), 6, 2008, Rio de Janeiro. Disponível em: < https:/ / etic2008.files.wordpress.com/2008/11/ ucpgiovanna.pdf>. Acesso em: 15 jan. 2017.

CAMPELLO, B. S. et al. Recursos informacionais em bibliotecas escolares: um estudo em biblioteca de internet. Belo Horizonte, 1998. Disponível em: <http://gebe.eci.ufmg.br/ downloads/T030.pdf>. Acesso em: 23 jul. 2014.

DAYRELL, J. A escola "faz" as juventudes? Reflexões em torno da socialização juvenil. Educação \& Sociedade, v. 28, p. 1105-1128, out. 2007. Disponível em: < http://www.scielo.br/ pdf/es/v28n100/a2228100.pdf> Acesso em: 17 fev. 2017

DEMO, P. Educar pela Pesquisa. Campinas: Autores Associados, 1996.
FIALHO, J. A formação do pesquisador juvenil: um estudo sob o enfoque da competência informacional. 2004. 131f. Dissertação (Mestrado em Ciência da Informação) - Escola de Ciência da Informação, Universidade Federal de Minas Gerais, Belo Horizonte.

FLICK, Uwe. Uma introdução à pesquisa qualitativa. Porto Alegre: Bookman, 2005.

FRANCISCATO, F. T. et al. Avaliação dos Ambientes Virtuais de Aprendizagem Moodle, TelEduc e Tidia - Ae: um estudo comparativo. Novas tecnologias na educação, v. 6, n. 1, dez., 2008. Disponível em: < http://seer.ufrgs.br/ renote/article/view/14509>. Acesso em: 01 jan. 2017.

FREITAS, L. G. de; FRANÇA, C. C. de; ALVES, L. A. de S. Juventude e aprendizagem com as tecnologias: uma reflexão a partir da abordagem histórico-cultural. In: SOUSA, C. A. de M. (Org.) Juventudes e tecnologias: sociabilidades e aprendizagens. Brasília, DF: Unesco, 2015. p. 193205.

GARCIA, S. R. de O. Ensino médio e educação profissional: breve histórico a partir da LDBEN n. 9394/96. In: AZEVEDO, J. C. de; REIS, J. T. Ensino médio e os desafios da experiência: movimentos da prática. São Paulo: Fundação Santillana: Moderna, 2014. p. 45-60.

GASQUE, K. C. G. D. Letramento informacional: pesquisa, reflexão e aprendizagem. Brasília: UnB, 2012. Disponível em: < http://repositorio. unb.br/bitstream/10482/13025/1/LIVRO_ Letramento_Informacional.pdf>. Acesso em: 10 mai. 2015.

.O pensamento reflexivo na busca e no uso da informação na comunicação científica. 2008, 240f. Tese (Doutorado em Ciência da Informação). Universidade de Brasília, Brasília.

GASQUE, K. C. G. D. G.; CASARIN, H. de C. S. Bibliotecas escolares: tendências globais. Em questão, Porto Alegre, v. 22, n. 3, p. 36-55, set/ dez. 2016. Disponível em: <http://dx.doi. org/10.19132/1808-5245223.36-55>. Acesso em: 5 jan. 2017. 
GASQUE, Kelley Cristine Gonçalves Dias; TESCAROLO, Ricardo. Sociedade da aprendizagem: informação, reflexão e ética. Ci. Inf., Brasília, v. 33, n. 3, p.35-40, set./dez. 2004.

GASQUE, K. C. G. D.; COSTA, S. M. de S. Comportamento dos professores da educação básica na busca da informação para formação continuada. Ciência da Informação, Brasília, v. 32, p. 54-61, 2003. Disponível em: http://www.scielo.br/pdf/ ci/v32n3/19024.pdf. Acesso em: 11 jan. 2017.

KEEN, Andrew. O culto do amador: como blogs, MySpace, YouTube e a pirataria digital estão destruindo nossa economia, cultura e valores. Rio de Janeiro: Jorge Zahar, 2009.

KENSKY V. M. Educação e tecnologias: o novo ritmo da informação. Campinas, SP: Papirus, 2007 (Coleção Papirus Educação).

KUENZER, A. Z. (Org.) Ensino médio: construindo uma proposta para os que vivem do trabalho. 4 ed. São Paulo: Cortez, 2009.

LEVINE, D. Visões da tradição sociológica. Rio de Janeiro: Zahar, 1997.

MACEDO, M. de M. A influência do letramento informacional na aprendizagem de estudantes do $9^{\circ}$ ano do ensino fundamental. 2015. 285f. Dissertação (Mestrado em Ciência da Informação) - Universidade de Brasília, Brasília.

MORAN, José Manuel; Massetto, M. T; BEHRENS, Marilda A.. Novas Tecnologias e Mediação pedagógica. Campinas-SP: Papirus, 2000.

MORRISSEY, J. O uso da TIC no ensino e na aprendizagem: questões e desafios. In: APARICI, R. (Coord.) Conectados no ciberespaço. São Paulo: Paulinas, 2012. p. 269-279.

MUNHOZ, A. S.. O estudo em ambiente virtual de aprendizagem: um guia prático. Curitiba: Ibpex, 2011.

PERUCCHI, V. A importância da biblioteca nas escolas públicas municipais de Criciúma,
Santa Catarina. Revista ACB: Biblioteconomia em Santa Catarina, v. 4, n. 4, p. 80-97, 1999. Disponível em: <http://basessibi.c3sl.ufpr.br/ brapci/v/a/8162>. Acesso em: 14 jan. 2016.

SILVA, N. dos S.; PIEDRAS, E. R. A maior aventura tecnológica da história da humanidade: expectativas sociais em relação às "novas" tecnologias de informação e comunicação. Conexão: comunicação e cultura. Caxias do Sul, v. 15, n. 30 (jul./dez. 2016), p. 153-175, 2016. Disponível em: < https://www.lume.ufrgs.br/ handle/10183/159747>. Acesso em: 21 out. 2017.

SIQUEIRA, E. Como viveremos em 2015: uma entrevista com os 50 maiores cientistas e futurologistas do mundo. São Paulo: Saraiva, 2004.

TAPSCOTT, D. A hora da geração digital: como os jovens que cresceram usando a internet estão mudando tudo, das empresas aos governos. Rio de Janeiro: Agir Negócios, 2012.

TODD, R.; KUHLTHAU, C. Information utilization for learning through the school library. Gill St. Bernard School, Bernard Township, NJ: CISSL, 2003.

TURKLE, Sherry. Alone Together. New York: Basic Books, 2011.

WELLER, W. A contribuição de Karl Mannheim para a pesquisa qualitativa: aspectos teóricos e metodológicos. Sociologia, Porto Alegre, ano 7, n. 13, jan./jun., 2006, p. 260-300.

WELLER, W. et al. Karl Mannheim e o método documentário de interpretação: uma forma de análise das visões de mundo. Soc. estado., Brasília , v. 17, n. 2, p. 375-396, Dec. 2002

Disponível em: < <http://www.scielo.br/ scielo.php?script $=$ sci_arttext\&pid $=$ S010269922002000200008\&lng=en\&nrm=iso>. Acesso em: 21 Out. 2015. http://dx.doi.org/10.1590/ S0102-69922002000200008.

WILSON, T. D. Human information behavior. Information Science Research, v. 3, n. 2, p. 49-55, 2000.Disponível em: <http://inform.nu/Articles/ Vol3/v3n2p49-56.pdf.>. Acesso em: 4 nov. 2015. 